\title{
Há pesquisa sobre ensino na saúde no Brasil?
}

\author{
Eliana Goldfarb Cyrino', Heider Aurelio Pinto², Felipe Proenço de Oliveira ${ }^{3}$, Alexandre Medeiros de Figueiredo $^{4}$, \\ Sidney Marcel Domingues ${ }^{4}$, Clélia Maria de Sousa Ferreira Parreira ${ }^{5}$ \\ 'Departamento de Saúde Pública, Faculdade de Medicina de Botucatu (FMB), Universidade Estadual “Júlio de Mesquita Filho" (UNESP) - Botucatu (SP), Brasil. \\ 22 ecretaria de Gestão do Trabalho e da Educação na Saúde (SGTES), Ministério da Saúde - Brasília (DF), Brasil. \\ ${ }^{3}$ Departamento de Planejamento e Regulação da Provisão de Profissionais de Saúde, SGTES, Ministério da Saúde - Brasília (DF), Brasil. \\ ${ }^{4}$ Departamento de Gestão da Educação na Saúde, SGTES, Ministério da Saúde - Brasília (DF), Brasil. \\ ${ }^{5}$ Curso de Graduação em Saúde Coletiva, Universidade de Brasília (UnB) - Ceilândia (DF), Brasil.
}

DOI: http://dx.doi.org/10.7322/abcshs.v40i3.787

A partir do título Há pesquisa sobre ensino na saúde no Brasil?, indicado pelos editores do fascículo temático da revista ABCS Health Sciences, nos propusemos a descrever o Edital Público Pró-Ensino na Saúde, resgatar sua história, as motivações e mobilizações para sua realização, alguns dados dos projetos desenvolvidos, estratégias para fomentar e garantir o desenvolvimento dos projetos aprovados no edital e caminhos partilhados para fomentar trocas e apoios aos grupos e aos pesquisadores. Foi feita a análise documental e de depoimentos divulgados em relatórios de seminários e reuniões dos projetos. Discutimos, buscando responder a pergunta título, alguns resultados do presente edital, reflexão sobre a indução do Pró-Ensino na Saúde e perspectivas para novos editais como proposta potente diante da necessidade de promover a formação docente para um novo modelo de graduação na saúde no e para o Sistema Único de Saúde (SUS) e a necessidade de construção de conhecimento na temática.

\section{ALGUNS MARCOS PARA O EDITAL PRÓ-ENSINO NA SAÚDE}

A formação e o ensino na saúde, no contexto nacional da reforma sanitária (e, na sequência, com a implantação do Sistema Único de Saúde - SUS) e no contexto internacional (com as reformas das graduações da saúde), ativaram movimentos voltados para a construção de mudanças nas graduações na saúde.

Currículos integrados, articulações ensino-trabalho, os projetos UNI, os movimentos coordenados pela rede Unida, o debate e a construção das Diretrizes Curriculares Nacionais e a organização das executivas de curso no Movimento Estudantil são exemplos de protagonismo por reformas do ensino que dialogam com os movimentos de mudança no setor da saúde ${ }^{1}$ (p.150).

Alguns autores merecem destaque como referências históricas dos últimos 40 anos na luta por mudanças nas graduações na saúde no Brasil, particularmente no esforço em tornar a educação na saúde mais próxima das necessidades de saúde da população. São eles: Magaldi $^{2}$, Ferreira ${ }^{3}$, Schraiber ${ }^{4}$, Kisil e Chaves $^{5}$, Marsiglia $^{6}$, Chompré $^{7}$, Campos $^{8}$, Almeida et al. ${ }^{9}$, Merhy $^{10}$, Ceccim e Feuerwerker ${ }^{11}$, Marins et al. ${ }^{12}$, entre outros.

Mais recentemente, o Programa Nacional de Reorientação Profissional em Saúde (Pró-Saúde) e o Programa de Educação pelo Trabalho em Saúde (Pet-Saúde) ${ }^{13}$ representaram ações conjuntas do Ministério da Saúde (MS) e do Ministério da Educação (MEC), voltadas a provocar mudança na formação de todas as profissões da saúde. O aumento de vagas de residências médicas em áreas prioritárias e as residências multiprofissionais do MS e a Reestruturação e Expansão das Universidades (Reuni) ${ }^{14}$, no MEC, com a abertura de novos cursos na saúde com projetos pedagógicos inovadores em novos territórios e com perspectiva interdisciplinar e interprofissional, têm ampliado o espectro de possibilidades de mudanças nas graduações da saúde.

O Programa Mais Médicos, em execução, desencadeou, em 2014, a revisão das Diretrizes Curriculares Nacionais (DCN) para a graduação médica, afirmando a centralidade da formação na Atenção Básica, a perspectiva de formação na rede de atenção à saúde no SUS e na relação ensino-serviço-comunidade, além da formação docente e de preceptores. As novas DCN da Medicina 
estão desenhadas a partir de eixos integradores: Atenção à Saúde, Gestão em Saúde e Educação na Saúde, que permeiam o processo formativo, indicando metodologias que privilegiam a participação do aluno na construção do conhecimento e propondo a formação de docentes e preceptores para conhecimento, reconhecimento e desenvolvimento destes eixos durante o curso. Para fortalecer a integração das instituições de educação superior (IES) responsáveis pela oferta dos cursos com as Secretarias Municipais e Estaduais de Saúde, na qualidade de gestores, será ofertado firmar Contratos Organizativos da Ação Pública Ensino-Saúde (COAPES) que viabilizem a reordenação da oferta de cursos e de vagas de Residência e a estrutura de serviços de saúde em condições adequadas ${ }^{15}$ (p.5).

Destacam-se, a seguir, marcos históricos de referência considerados fundamentos ao Edital Pró-Ensino na Saúde, tema deste artigo.

Nos anos 1990 ocorreu em nosso país um movimento amplo com foco na transformação da escola médica, liderado pela Comissão Interinstitucional Nacional de Avaliação do Ensino Médico (CINAEM) ${ }^{16}$. Deste participaram do processo a Direção Executiva Nacional dos Estudantes de Medicina (DENEM), diversas entidades, como Conselho Federal de Medicina (CFM), Conselho Regional de Medicina do Estado de São Paulo (CREMESP) e Associação Brasileira de Ensino Médico (ABEM), e um grande grupo de escolas médicas, professores, estudantes, profissionais da saúde, representantes da sociedade civil e outras instituições. Em que pese a ruptura desse processo nos anos que se seguiram, já no início dos anos 2000 esse movimento com certeza influenciou as bases das DCN dos cursos da área da saúde, implantadas a partir de 2001. A perspectiva apontada na CINAEM, de redesenhar a escola médica com uma maior articulação às demandas e às necessidades de saúde da população e maior integração ao SUS, em toda a rede, foi fundamental para mudanças que ocorreriam nos anos que a sucederam nas profissões da saúde.

A partir da aprovação das DCN dos cursos da área da saúde, o MS, em conjunto com o MEC, vem formulando uma série de políticas, propostas e programas destinados à reorientação da formação em saúde, em consonância com as DCN e com o desenvolvimento do SUS. Tais propostas vêm sendo orientadas para ampliar e qualificar o ensino nas redes de atenção no SUS.

Em 2003, a recém-criada Secretaria de Gestão do Trabalho e da Educação na Saúde (SGTES) do MS possibilitou novo incremento ao processo de mudança curricular nas graduações na saúde. Apresentou diretrizes de apoio às iniciativas inovadoras para articular a rede de serviços, a gestão e o controle social do SUS às instituições formadoras de profissionais da área da saúde. Ao criar a Política Nacional de Educação Permanente em Saúde e promover práticas de educação envolvendo os trabalhadores dos serviços buscando a integralidade da atenção à saúde da população, colocou a educação e a necessidade de integração dos serviços com as instituições formadoras no centro da agenda do SUS, ambas demandando mudança das práticas de educação e formação, mas que poderiam se reforçar ${ }^{17}$.

O MS e o MEC lançaram, em 2004, o Aprender SUS ${ }^{17}$, como um conjunto de estratégias para viabilizar e fortalecer relações de cooperação entre as instituições de educação superior (IESs) e o sistema de saúde em todos os âmbitos (ensino, produção de conhecimentos e prestação de serviços). A implementação das DCN, pela educação, e a adoção da integralidade como eixo orientador dos processos de formação, pela saúde, eram os eixos da política para a mudança na graduação das profissões da área da saúde. Dentre as várias iniciativas do Aprender SUS, destacam-se: as Vivências e Estágios na Realidade do SUS (VER-SUS), a constituição do Fórum Nacional de Educação das Profissões da Saúde (FNEPAS) e a formação de ativadores de processos de mudança ${ }^{18}$.

O Curso de Especialização em Ativação de Processos de Mudança na Formação Superior de Profissionais de Saúde da Escola Nacional de Saúde Pública, Rede Unida e MS, realizado entre 2005-2006, foi uma oportunidade única para o desenvolvimento docente em rede colaborativa, com participação de docentes das diferentes profissões da saúde desde uma perspectiva inovadora, o incremento de projetos criativos de educação a distancia (EP) e uma possibilidade de aproximação do trabalho problematizador desenvolvido coletivamente. O movimento gerado no curso dos ativadores fez sentido na ampliação do processo de mudança na educação superior na saúde e talvez tenha sido a maior mobilização para formação docente na saúde, tanto por seu impacto no trabalho docente, na formação de redes colaborativas, como pelo número de professores e profissionais de saúde que dele participaram. Segundo levantamento recente, foram certificados 698 ativadores, sendo 101 tutores e 597 especializandos ${ }^{18}$.

Embora não se tratasse de uma novidade, o Curso de Ativadores trouxe à tona as necessidades de formação de professores para a mudança das graduações, de desenvolvimento de pesquisas e de produção de novos conhecimentos no campo do ensino e da docência em saúde. Na sequência desse curso foram desencadeadas com maior visibilidade, em diversos eventos promovidos pela Associação Brasileira de Educação Médica e outras associações de ensino, discussões sobre a necessidade de formação e desenvolvimento docente e de pesquisas em ensino e docência na saúde.

Identificou-se a principal característica das políticas de formação de professores universitários, no que se refere à formação pedagógica e didática:

O silêncio. Enquanto nos outros níveis de ensino, o professor é bem identificado, no ensino superior parte-se do princípio de que sua competência advém do domínio da área de conhecimento na qual atua. Em suma, a formação é para a pesquisa. E a pesquisa como recorte - extremamente especializada ${ }^{19}$ (p.24).

Entendeu-se que não seria possível caminhar para a inovação, a reforma ou a transformação da educação universitária sem tomar o professor como elemento essencial desse processo e então reconhecer sua identidade, subjetividade, contradições e convicções próprias 
sobre o que é valioso e importante do ponto de vista educacional. Nessa posição, o professor não está afastado de pressões externas e internas à instituição de ensino e suas alternativas educacionais não surgem de forma abstrata, mas se originam do conjunto de relações objetivas que se dão na sociedade. No caso da escola médica, pode se dizer que

conserva e transmite em seu discurso e sua prática, quase sempre, uma ideologia que tenta colocar a Medicina como ciência neutra, à frente da humanidade, visando exclusivamente à saúde, à vida e ao bem estar, impossibilitando criticá-la como ciência e prática. Evitando relacionar a medicina com a estrutura social, tal concepção idealista, procura desvincular a escola médica das práticas políticas, econômicas e ideológicas ${ }^{20}$ (p.148).

Para além da falta de formação do docente e da percepção do contexto político do seu trabalho, atualmente se reconhece como questões centrais no trabalho do docente nas universidades, reconhecidos por sua produção intelectual: ser um bom investigador, obter recursos para sua pesquisa, publicar em periódico de prestígio na área e dar algumas aulas na graduação ou na pós-graduação. O processo de promoção docente concentra-se em pesquisas, publicações e obtenção de recursos das agências financiadoras. É esperado do professor que seja, em primeiro lugar, um bom investigador na sua especialidade e, depois, um professor. Ou seja, não se valoriza a prática docente nem a pesquisa no ensino.

Para professores que atuam na clínica, há ainda um terceiro e fundamental problema: ser docente no trabalho clínico, na assistência. $\mathrm{Na}$ perspectiva de mudança, isso significa ensinar a prática clínica por cuidado, vínculo, acolhimento, afeto, atitude, raciocínio, ética, troca, na prática da atenção. No cuidado ao paciente, à família e à comunidade, o professor, como mediador do processo de ensino-aprendizagem, deve permitir uma formação que tenha sentido ao aluno, centrada na pessoa sob cuidado, o que envolve professores, alunos, pacientes, profissionais de saúde, preceptores ${ }^{21}$ e comunidade, projeto terapêutico, rede de atenção. O caráter mediador da competência técnica se expressa no interior do projeto político ${ }^{22}$. Promover o ensino na clínica significa compreender que

não é possível aprender a cuidar em uma aula, duas ou vinte, o desenvolvimento do cuidar deve envolver o contato com o outro e as relações entre as pessoas. Essas aprendizagens são dinâmicas e imprevisíveis. A responsabilidade de cuidar do outro exige uma reavaliação constante por parte do profissional para que ele tenha condições de atender às necessidades do outro e às suas também, como pessoa $\mathrm{e}$ como profissional, à medida que as dificuldades, os impasses e as soluções apareçam no dia-a-dia do trabalho' ${ }^{1}$ (p.171).

É no bojo de necessidades e contradições que surgem questões como: o sentido da docência na graduação e do trabalho do professor universitário, a valorização do processo de ensino, da docência, da prática clínica comprometida com a integralidade do cuidado no SUS, a maior autonomia do estudante e do paciente, a presença de uma pedagogia comprometida com o processo criativo, a realização e valorização de pesquisas sobre ensino na saúde e a publicação dos estudos, objeto central do edital a que este texto se refere.

\section{O Programa Nacional de Desenvolvimento Docente em Saúde: Pró-Ensino na Saúde: o edital e a seleção}

Como parceria da Coordenação de Aperfeiçoamento de Pessoal de Nível Superior (CAPES) ${ }^{23,24}$ com a SGTES, do MS, a CAPES lançou, em 2010, o Edital no 24/2010, tendo sido concebido no âmbito do Programa Nacional de Apoio ao Ensino e à Pesquisa em Áreas Estratégicas (PRONAP). Esta iniciativa compôs uma série de políticas e ações indutoras, realizadas pelo MS em parceria com o MEC, com vistas à consolidação do SUS. Nesse caso específico, buscava-se estimular e ampliar a formação de professores e o desenvolvimento de pesquisas sobre ensino nas diferentes áreas da saúde no interior dos programas de pós-graduação existentes e consolidados.

A proposta do Edital Pró-Ensino na Saúde estava inserida na consolidação da Política Nacional de Formação dos Profissionais da Saúde, implementada a partir de 2003, com a criação da SGTES no MS. Os projetos poderiam ser propostos por grupos de professores e pesquisadores de instituições brasileiras públicas e privadas, sem fins lucrativos, com programas de pós-graduação stricto sensu, reconhecidos pelo MEC, com nota mínima 4, conferida pelo Sistema de Avaliação CAPES. Poderiam ser projetos de uma instituição, mas estimulou-se o estabelecimento de parcerias e redes de centros de pesquisa e de pesquisadores ${ }^{23,24}$.

O programa objetivava possibilitar a produção de pesquisas científicas e tecnológicas e a formação de mestres, doutores e pós-doutores na área de ensino na saúde. A ideia era contribuir para desenvolver essa formação, considerada estratégica para o desenvolvimento do SUS. Entre os itens financiáveis estavam bolsas no país nas modalidades mestrado acadêmico, doutorado, pós-doutorado e de professor-visitante (nacional ou estrangeiro). O valor de financiamento de cada projeto foi de até R\$ 220 mil por ano, incluindo todas as despesas, em um total de R\$ 820 mil máximo por iniciativa. Os projetos deveriam ser desenvolvidos entre 2011 e 2016, com 5 anos para a execução das atividades.

Partiu-se do pressuposto de que, ao estimular a criação de linhas ou de áreas de concentração sobre ensino nos programas, seria possível aperfeiçoar a formação docente na pós-graduação e, assim, contribuir para o avanço das mudanças nas graduações da saúde, especialmente no momento de expansão de vagas e cursos no ensino superior no país. No edital se considerou que, apesar da diversidade de temas pertinentes ao Ensino na Saúde, seria conferida prioridade às seguintes áreas temáticas ${ }^{23}$ : 
- gestão do ensino na saúde;

- $\quad$ currículo e processo ensino-aprendizagem na graduação e pós-graduação em saúde;

- $\quad$ avaliação no Ensino na Saúde;

- $\quad$ formação e desenvolvimento docente na saúde;

- $\quad$ integração universidades e serviços de saúde;

- $\quad$ políticas de integração entre saúde, educação, ciência e tecnologia;

- $\quad$ tecnologias presenciais e a distância no Ensino na Saúde.

Para a CAPES, com sua reestruturação em 2007, propor essa iniciativa responderia a demanda voltada ao desenvolvimento de ações em parceria com vários ministérios, fundações estaduais de apoio à pesquisa e outras instituições, com ações voltadas principalmente à formação de pessoal qualificado de alto nível em áreas consideradas estratégicas para o Estado brasileiro ${ }^{24}$. Assim, o Pró-Ensino foi considerado destaque dos programas estratégicos, com ações para qualificar jovens doutores e fomentar a pesquisa científica em áreas prioritárias ao SUS ${ }^{24}$.

Segundo Haddad, em entrevista à CAPES, o Pró-Ensino na Saúde se desenvolveria

junto ao PET-Saúde no fortalecimento da integração entre ensino e serviço, como parte do Pró-Saúde, cujo objetivo era apoiar as instituições de ensino superior a avançarem na implementação das diretrizes curriculares nacionais para os cursos de graduação na saúde ${ }^{24}$.

Nessa perspectiva, estimava-se que aproximadamente 600 cursos de graduação estariam participando do programa, com alcance de mais de 100 mil estudantes ${ }^{24}$.

No total, 47 projetos foram submetidos à análise. Destes, 31 projetos foram selecionados, resultando na articulação de cerca de 42 IESs, envolvendo mais de 40 programas de pós-graduação, todos com notas CAPES 4, 5, 6 ou 7. Na proposta do edital cada projeto deveria incluir a formação de, no mínimo, seis mestres e dois doutores, para os quais seriam concedidas bolsas de estudo nessas modalidades. Assim, esperava-se, no mínimo, a formação de 186 mestres e 62 doutores.

A partir de dados de 28 projetos, segundo pesquisa, tema de doutorado desenvolvido no âmbito do projeto da Universidade Federal de São Paulo (UNIFESP),

em relação à inserção discente e proposta formativa apresentada pelos projetos, estima-se a oferta de vagas para formação de 411 profissionais da área da saúde e afins, assim distribuídos: vagas em nível de mestrado (213/51,1\%); seguida de vagas para o doutorado (154/38\%), e ainda 44 (10,9\%) vagas para o estágio pós-doutoral ${ }^{25}$ (p.11).

Ou seja, a expectativa de formação superou em muito o número proposto no edital.

Por meio de informação obtida por técnicos da CAPES, estes foram os projetos selecionados, segundo o título, IES responsável e área de avaliação da CAPES (Tabela 1).

Foi possível observar uma maior concentração de projetos nas áreas temáticas: "formação e desenvolvimento docente na saúde" e "currículo e processo ensino-aprendizagem na graduação e pós-graduação em saúde".

A maior parte dos projetos foi iniciada no princípio de 2011, mas alguns, por questões técnicas, começaram no segundo semestre de 2011.

Segundo estudo da UNIFESP, atualmente em desenvolvimento, com dados de 28 projetos do Pró-Ensino, a grande maioria (19) das IESs participantes do Pró-Ensino estabeleceu e/ou desenvolveu parceria com outros programas e políticas do MS e do MEC, chamando a atenção à adesão ao Pet-Saúde e ao Pró-Saúde ${ }^{25}$ (Figura 1).

Deve-se assinalar que paralelamente ao Edital no 24/2010 e como uma proposta complementar ao processo, em ação conjunta entre o Departamento de Hospitais e Residências da Secretaria de Educação Superior, do MEC, e o Departamento de Gestão da Educação na Saúde da Secretaria de Gestão do Trabalho e da Educação na Saúde, do MS, elaborou-se documento para incentivo à Pós-Graduação na área do Ensino na Saúde - Pró-Ensino na Saúde (Programa Nacional de Reorientação da Formação Profissional na Saúde) denominado "Recomendações para Elaboração de Projetos de Mestrados Profissionais em Ensino na Saúde”26, cujo primeiro edital direcionado para o mestrado profissional em Ensino na Saúde teve cerca de 15 programas aprovados e em execução, no período de 2011 a 2013.

\section{ENCONTROS E APROXIMAÇÕES}

Em novembro de 2011, no 49 Congresso Brasileiro de Educação Médica, em Belo Horizonte, ocorreu uma primeira reunião entre os projetos do Pró-Ensino na Saúde aprovados, com o objetivo de esclarecer sobre o desenvolvimento do programa e mesmo sobre a implementação de cada projeto ${ }^{24}$. 
Tabela 1: Projetos selecionados, segundo o título, instituição de ensino superior responsável e área de avaliação da Coordenação de Aperfeiçoamento de Pessoal de Nível Superior

\begin{tabular}{|c|c|c|c|}
\hline $\mathbf{N}^{\circ}$ & Título do projeto & $\begin{array}{l}\text { IES } \\
\text { responsável }\end{array}$ & Área de avaliação \\
\hline 1 & Ensino na Saúde: Caminhos para a superação dos desafios na formação profissional para o SUS. & UFSC & Enfermagem \\
\hline 2 & A formação de professores no contexto do SUS: Políticas, ações e construção do conhecimento. & USP & Enfermagem \\
\hline 3 & $\begin{array}{l}\text { Estudo da formação do profissional de saúde no contexto de inovações curriculares, da capacitação } \\
\text { pedagógica de professores e da integração ensino-serviço na rede SUS. }\end{array}$ & UFRJ & $\begin{array}{l}\text { Ensino de Ciência } \\
\text { e Matemática }\end{array}$ \\
\hline 4 & Inserção de tecnologias a distância combinadas com presenciais no ensino na área da saúde. & UFRGS & Farmácia \\
\hline 5 & Formação em educação superior nas profissões da saúde. & USP & Medicina I \\
\hline 6 & $\begin{array}{l}\text { Desenvolvimento de competências gerais e específicas nos vários cenários de ensino- } \\
\text { aprendizagem dos estudantes de medicina, odontologia e enfermagem: situação atual dos } \\
\text { currículos, implantação e avaliação de metodologia ativas. }\end{array}$ & UFC & Medicina I \\
\hline 7 & Implementação do núcleo de ensino e pesquisa em educação na saúde da FMABC. & FMABC & Medicina I \\
\hline 8 & Avaliação do ensino na saúde: formação de multiplicadores para ações de qualidade. & UNICAMP & Medicina I \\
\hline 9 & Ensino na saúde: uma proposta integradora para o SUS. & UFCSPA & Medicina I \\
\hline 10 & Orientação pedagógica do trabalho docente em saúde. & FAMERP & Medicina I \\
\hline 11 & Docência na saúde. & PUC-RS & Medicina I \\
\hline 12 & $\begin{array}{c}\text { Inovação em docência universitária: uma proposta de (trans)formação no processo de ensino e } \\
\text { aprendizagem para os cursos da área de saúde }\end{array}$ & UFV & Medicina I \\
\hline 13 & Ensino, saúde e desenvolvimento: rede de saberes e práticas. & FPP & Medicina II \\
\hline 14 & Tecnologias educacionais interativas para potencialização da educação na saúde. & USP & Medicina II \\
\hline 15 & $\begin{array}{c}\text { Projeto de criação da linha de pesquisa em ensino na saúde do programa PG em ciências da saúde } \\
\text { na UFG. }\end{array}$ & UFG & Medicina II \\
\hline 16 & $\begin{array}{l}\text { Projeto de criação da linha de pesquisa e apoio ao ensino na saúde no mestrado profissional de } \\
\text { saúde coletiva da FCMSCSP. }\end{array}$ & FCMSCSP & Saúde Coletiva \\
\hline 17 & $\begin{array}{l}\text { Fortalecimento do ensino na saúde no contexto do SUS: uma proposta interdisciplinar da UnB na } \\
\text { Região Centro Oeste. }\end{array}$ & UnB & Psicologia \\
\hline 18 & Formação para a docência de ensino superior na área de pesquisa clinica em doenças infecciosas. & FIOCRUZ & Saúde Coletiva \\
\hline 19 & $\begin{array}{l}\text { Integração universidade, serviços de saúde e comunidade na Faculdade de Medicina de Botucatu: } \\
\text { construindo novas práticas de formação e pesquisa. }\end{array}$ & UNESP & Saúde Coletiva \\
\hline 20 & Educação e saúde: bases e epistemológicas da formação de profissionais do SUS. & FUFPI & Serviço Social \\
\hline 21 & $\begin{array}{l}\text { Projeto de formação de recursos humanos no nível de mestrado e doutorado em educação para } \\
\text { profissionais de saúde com ênfase no ensino na saúde para o SUS. }\end{array}$ & UFMT & Educação \\
\hline 22 & $\begin{array}{c}\text { Políticas de formação em educação física e saúde coletiva: atividade física/práticas corporais do } \\
\text { SUS. }\end{array}$ & UFRGS & Educação Física \\
\hline 23 & Avaliação do estudante e do ambiente de ensino nos cursos da área da saúde. & USP & Medicina I \\
\hline 24 & Integração entre Universidade e Política de Saúde: Intersetorialidade e Ensino na Saúde. & PUC-RS & Serviço Social \\
\hline 25 & Ensino integrado: assistência, docência e inovação em Medicina Laboral e Saúde. & UERJ & Biologia \\
\hline 26 & Educação e saúde na promoção à saúde da criança e do adolescente: um contexto interdisciplinar. & UFPE & Educação \\
\hline 27 & $\begin{array}{l}\text { Estudo da relação entre o uso racional da propedêutica complementar e a prática do método clínico } \\
\text { centrado na pessoa. }\end{array}$ & UFMG & Patologia \\
\hline 28 & $\begin{array}{c}\text { Laboratório de Pesquisas, Ensino e Gestão do Conhecimento, da Educação e do Trabalho na } \\
\text { Saúde. }\end{array}$ & UFC & Odontologia \\
\hline 29 & $\begin{array}{c}\text { Avaliação do potencial Biológico de Extratos de Própolis Vermelha da Região de Brejo Grande/SE } \\
\text { para aplicação no Sistema Único de Saúde. }\end{array}$ & UCS & Biotecnologia \\
\hline 30 & $\begin{array}{c}\text { Formação Profissional para a Integralidade no Cuidado: articulando formação, avaliação e } \\
\text { integração com o SUS. }\end{array}$ & Unifesp & $\begin{array}{l}\text { Ensino em } \\
\text { Ciências da Saúde }\end{array}$ \\
\hline 31 & Pró-Ensino na Saúde EEUSP/UEMS - Formação docente para o ensino e o cuidado à saúde. & USP & Enfermagem \\
\hline
\end{tabular}

IES: instituição de ensino superior.

Fonte: Pesquisa documental do projeto "O ensino na saúde como objeto de pesquisa na pós-graduação stricto sensu: uma análise do programa Pró-Ensino na Saúde", $2015^{25}$.

Em setembro de 2013, ocorreu o Seminário de Avaliação dos Projetos Aprovados no Programa de Apoio ao Ensino e à Pesquisa Científica e Tecnológica em Ensino na Saúde (Pró-Ensino na Saúde), em Brasília, na Sede da CAPES, com a representação de 30 dos projetos aprovados. O objetivo do seminário voltava-se a oportunizar o compartilhamento de experiências entre os coordenadores, pesquisadores e docentes dos projetos e de reflexões relativas ao desenvolvimento dos projetos, de forma a trazer ao conjunto dos grupos de pesquisa e à CAPES as dificuldades para condução e implementação dos projetos.

Acima de tudo, para a SGTES, propositora e maior financiadora do edital, naquele momento se buscava avançar para uma repactuação entre todos na perspectiva de fortalecer os projetos como um movimento de articulação pautado na necessidade de mudanças na formação em saúde.

Nesse evento ficou claro que, embora o Pró-Ensino na Saúde tenha sido uma ação indutora da CAPES/MS, para os coordenadores dos programas de pós-graduação alguns entraves e desafios estavam presentes nos dois primeiros anos de execução para o êxito e o grande 


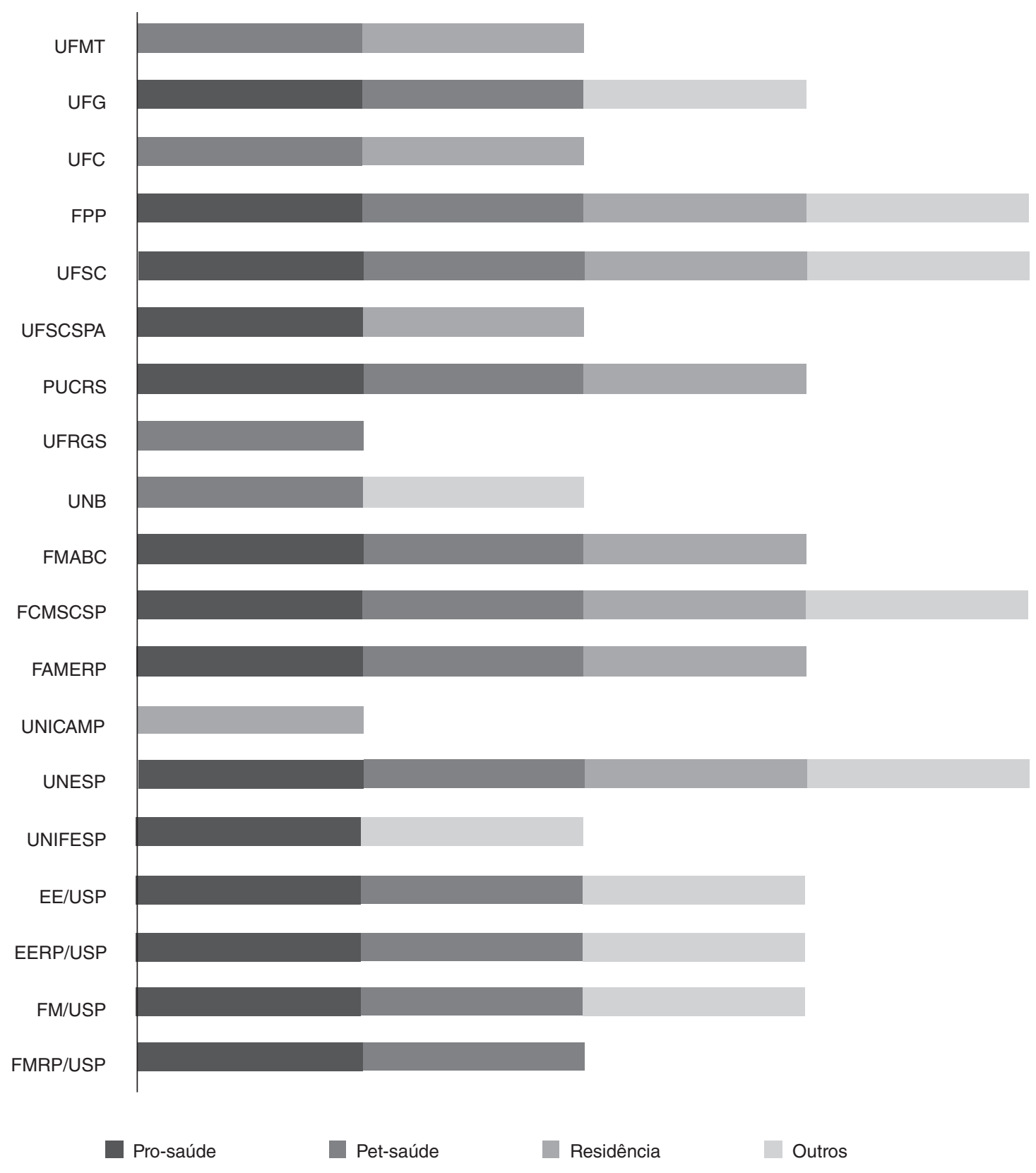

Figura 1: Políticas indutoras desenvolvidas nas instituições de ensino superior referidas nos projetos do programa Pró-Ensino na Saúde, 2010

impacto social esperado. Assim, o grupo de pesquisadores, em parceria com representantes da SGTES/MS, apresentou documento enviado ao Conselho Técnico-Científico da CAPES, com as seguintes considerações:

- A necessidade de uma maior comunicação entre a CAPES e as coordenadorias de áreas sobre a existência e os objetivos desses projetos, uma vez que se verificou um desconhecimento da iniciativa como indutora de política formadora de mestres e doutores para a docência na graduação, especialmente nesse momento de expansão do ensino superior público no país. Essa situação implicou, em certa medida, em desconforto dos projetos diante de possíveis impactos negativos na avaliação dos programas que os acolheram e em risco para um diálogo com maior eficiência e possibilidades de trabalhos conjuntos e cooperativos entre os pesquisadores.

- O fato de os programas de pós-graduação tradicionais e consolidados, muitos na área de Medicina I e II, terem acolhido professores na linha de pesquisa de Ensino na saúde, em resposta à indução da CAPES/MS, a despeito de suas áreas temáticas prioritárias não serem nesse campo. Tal fato significou, para alguns programas, publicações resultantes dos estudos em ensino na saúde em periódicos não necessariamente relacionados com aqueles de maior impacto nas suas próprias áreas, gerando desinteresse na incorporação 
dessas produções. Assim, em tempos de avaliação trienal, quem estava pesquisando Ensino em Saúde percebeu que sua publicação poderia ser rejeitada pelos programas aos quais estavam vinculados por considerarem que a produção não era compatível com aquela área. Em consequência, a avaliação da CAPES, ao usar a mesma métrica das áreas dos programas de pós-graduação, poderia ser a contra a indução do desenvolvimento do ensino na saúde em programas tradicionalmente bem avaliados.

- Que a CAPES, que se mostrou mobilizada para induzir a formação de professores e a produção qualificada na área de ensino na saúde, poderia atribuir valor aos programas de pós-graduação que acolheram projetos e professores do ensino na saúde pela relevância que vem trazendo à formação e ao desenvolvimento docente. Ou que avaliasse esses professores e sua produção dentro de uma métrica de impacto condizente com o escopo do ensino na saúde, em uma reafirmação da importância da pesquisa nessa área, valorizando a formação docente para o ensino superior.

- Discutir a possibilidade de reconhecimento da formação docente como um tema transversal em todas as áreas e capaz de gerar indicadores próprios para efeito das avaliações nos distintos programas.

Esse seminário significou para todos os presentes, professores, pesquisadores, alunos da pós, técnicos do MS e do MEC, uma possibilidade de troca, movimento, encontro e fortalecimento dos projetos. Também foi um momento de percepção da riqueza das pesquisas e, de certa forma, uma possibilidade de trazer todos para o centro da proposta: formação docente para a mudança nas graduações e perspectiva de construção de conhecimento no tema ensino na saúde.

Seguiram-se diversas reuniões de trabalho com o objetivo de trocas, propiciar parcerias e fortalecer a proposta do edital nos projetos em execução. Vários eventos regionais foram realizados para discutir e divulgar as pesquisas em desenvolvimento. Nas reuniões eram apresentados resultados de dissertações e teses, publicações de livros e artigos de revista e sempre a possibilidade de algum apoio àqueles pesquisadores que apresentavam entraves locais para o progresso do projeto. Nesses encontros também se pautou a necessidade de continuidade do Pró-Ensino a partir de novos editais, como resposta à necessidade de se promover a formação do docente para um novo modelo de formação na saúde e para a construção de conhecimentos na temática.

Em 2015, o evento "Encontro dos projetos Pró-Ensino/CAPES na FCM/UNICAMP”, organizado em parceria com a SGTES, mostrou evidências sobre a possibilidade de ampla produção acadêmica resultante dos projetos em andamento. A partir da leitura dos 73 resumos resultantes de pesquisas, aprovados e selecionados para apresentação nesse encontro dos Projetos Pró-Ensino, foi possível evidenciar os seguintes temas: currículo e metodologias de ensino; metodologia de pesquisa em educação médica; determinantes sociais e compromisso social da escola médica; cenários de prática e integração ensino-serviço; avaliação de estudantes nos processos de ensino aprendizagem, do curso e do egresso; educação a distância, tecnologia de informação e comunicação em saúde; extensão universitária; profissionalização e capacitação docente; residência médica e multiprofissional e pós-graduação e interprofissionalidade.

A seguir apresenta-se um breve relato sobre os trabalhos apresentados no referido evento.

Em relação ao currículo e às metodologias de ensino, as pesquisas analisam as mudanças ocorridas após a publicação das DCN 2001 e 2002, avanços e desafios das experiências de integração curricular. Elas analisam, também, o desenvolvimento de Projetos Pedagógicos de Cursos (PPC), a educação permanente de profissionais da saúde na Atenção Básica, além de elaborar e implementar cursos e disciplinas de graduação na modalidade a distância.

Iniciativas como a instalação de núcleos de pesquisa em ensino na saúde foram relatadas como processos para viabilizar projetos em ensino, pesquisa e extensão na interface educação-saúde; promover uso das tecnologias da informação e comunicação no ensino; ampliar a produção científica e tecnológica e a inovação diante dos desafios da consolidação das políticas públicas em saúde e educação; promover formação e qualificação de recursos humanos para atuação na pós-graduação, graduação, serviços de saúde e educação; estimular o intercâmbio de profissionais entre as instituições.

As pesquisas que discutiram impactos da determinação social na saúde evidenciaram a necessidade de se conhecer os aspectos sociais, demográficos, econômicos, étnicos e de orientação sexual. O que foi apontado também pelos projetos que abordam a saúde das populações: negra, transexuais, de usuários de drogas, em processos de reassentamento, em situação de violência e ou de vulnerabilidade nas relações afetivo-sexuais. Vale destacar pesquisas sobre políticas de cotas sociais para ingresso no ensino superior nas instituições públicas, cujo resultado mostrou não haver diferença no rendimento acadêmico desses ingressantes, seja durante a graduação ou mesmo nos concursos para residência.

Em relação aos cenários de prática e integração ensino-serviço, percebe-se que os projetos analisaram trajetórias, concepções, motivações, expectativas e a influência do Pró-Saúde e do PET-Saúde em suas respectivas instituições e as competências a serem desenvolvidas no processo formativo para a atuação no SUS. Menciona-se a construção de ações voltadas a ensino, pesquisa, formação e qualificação profissional em saúde a partir da integração entre os programas de pós-graduação para qualificação curricular, para fortalecimento da relação entre ensino, pesquisa, formação e qualificação profissional em saúde, em consonância com a política de saúde, no âmbito da graduação e da pós-graduação e da produção científica na área de ensino na saúde.

Quanto à avaliação de estudantes nos processos de ensino-aprendizagem, verificou-se a criação de instrumentos de apoio à avaliação das competências gerais de estudantes de graduação, com resultados positivos e a sua indicação para utilização. No caso específico da Medicina, em 
estudo de egressos, identificou-se que as escolas médicas brasileiras têm promovido mudanças curriculares após as Diretrizes Curriculares do Curso de Medicina de 2001 para fortalecer o SUS. Quanto à avaliação de cursos e de instituições, foram encontrados estudos sobre a percepção de estudantes e docentes acerca das práticas de ensino-aprendizagem utilizadas, sobre tipologia e tendências de mudança.

A educação a distância e a tecnologia de informação e comunicação em saúde foram estudadas identificando-se o estado atual e potencial da utilização pedagógica de ambientes eletrônicos de aprendizagem, a partir das percepções de docentes e discentes no contexto do ensino na saúde. A análise e reflexão sobre os ambientes virtuais de aprendizagem (AVAs) revelados pode ser útil como instrumento de avaliação na utilização desse recurso e sobre a eficácia dessa estratégia para o processo de ensino e aprendizagem na graduação e na pós-graduação.

Pesquisas ressaltam a investigação dos processos de realização de educação permanente em saúde e seus efeitos nos processos de trabalho voltados à integralidade do cuidado.

Quanto à profissionalização e capacitação docente, estudos demonstraram a necessidade de se compreender como os professores constroem seu desenvolvimento profissional para docência a partir de sua inserção na educação superior e de que forma profissionais da saúde buscam realizar formação específica para atuar como preceptores. Percebe-se a necessidade de maior investimento na formação docente dos profissionais da saúde.

A residência multiprofissional é abordada segundo a análise dos princípios, concepções e práticas da educação interprofissional presentes nos Programas da Residência Multiprofissional em Saúde. Como contribuição se traz a discussão da educação interprofissional como subsídio às adequações para o trabalho em saúde, o qual exige mudanças de atitude pessoal e profissional.

Há pesquisa sobre a percepção de discentes, docentes e coordenadores de Mestrados Profissionais em Ensino na Saúde (MPES), os quais relatam que a experiência construída tem potencial mobilizador e transformador das práticas profissionais em ensino na saúde, contribuindo para as mudanças curriculares. Há a necessidade de os MPES se apropriarem de uma identidade não somente determinada pela sua área temática, mas, fundamentalmente, pelo enorme desafio de integrar a pesquisa ao seu desenvolvimento profissional e transformar realidades de ensino e trabalho em saúde.

Enfim, as pesquisas têm revelado o impacto positivo que a indução do MS e do MEC trouxe para a produção de novos conhecimentos em uma área recém-criada, ainda pouco valorizada na academia e nas revistas científicas e pouco visível nos serviços de saúde. A adesão das instituições mostrou a disposição e a coragem de pesquisadores em investir em uma área sem tradição em pesquisa acadêmica, mas de forte apelo e implicação na reorientação da formação em saúde preconizada pelas políticas nacionais. Ademais, a experiência com o Pró-Ensino revelou que, a despeito da dispersão de trabalhos nessa área, existe uma disposição e pontos de convergência que possibilitaram a criação de uma rede de colaboração no âmbito da pesquisa em ensino na saúde.

\section{VOLTANDO A PERGUNTA INICIAL: HÁ PESQUISA SOBRE ENSINO NA SAÚDE NO BRASIL?}

Nossa aposta é afirmar que sim, há pesquisa sobre ensino na saúde no Brasil e há evidências de que o edital aqui apresentado provocou a formação docente e ampliou as pesquisas sobre ensino na saúde, independentemente do grau de adesão dos distintos projetos aos itens e às orientações constantes no edital. Há uma variedade de possíveis olhares quando se avalia um programa de governo, e a observação atenta nos permite apreender suas repercussões.

A indução oportunizada pela publicação do Edital Pró-Ensino e pela adesão das instituições participantes criou espaço para que se pudesse relacionar a formação de professores aos aspectos relevantes da produção da própria profissão docente, além de trazer — para a centralidade do debate - a implicação das instituições formadoras na produção de conhecimentos que incidem sobre os modos de pensar a formação desde uma perspectiva articulada com as políticas intersetoriais de reorientação da formação em saúde em curso no país.

As pesquisas que têm sido desenvolvidas no âmbito dos diferentes projetos vêm resultando em um entendimento de que a formação e o desenvolvimento docente vão além da dimensão pedagógica da experiência formativa em si ${ }^{27}$ para alcançar, também, uma compreensão dessa formação como um processo interativo, no qual a docência e o ensino na saúde demandam a criação de redes colaborativas e coletivas de trabalho que produzam conhecimentos sobre os valores próprios da ação docente e se configurem como mais uma estratégia de harmonização entre formação e trabalho em saúde.

Para responder a pergunta sobre a existência ou não de pesquisa sobre ensino na saúde no Brasil é importante considerar as contribuições que essa experiência tem trazido para a gestão da educação e do trabalho em saúde, uma vez que considera as transformações necessárias no perfil dos profissionais de saúde que atuarão no SUS, sobretudo em função de vivermos em tempos de mudanças constantes, nas quais as tensões e as complexidades, tanto na saúde como no campo social, também se encontram expressas no cotidiano do trabalho em saúde ${ }^{28}$.

Mas os dilemas da prática docente e do ensino em saúde não são meramente instrumentais: exigem que se trabalhe no sentido de criar, ampliar e diversificar modelos, técnicas, conhecimentos e práticas formativas que levem ao estabelecimento de distintas relações entre o saber pedagógico, o saber científico e o saber oriundo da experiência no e para o trabalho. Para isso, há de se ter estudos, fortemente vinculados às práticas educativas, com mecanismos claros de disseminação de seus achados para sua rápida apropriação e uso. 
Para os coordenadores institucionais do Pró-Ensino, nesse curto período de sua implementação, houve efetivamente ganhos intra e interinstitucionais, parte pela criação de mecanismos para o intercâmbio entre profissionais de saúde com atuação nos serviços e academia, tendo a prática em saúde como objeto de estudo, parte pela diversificação na utilização e produção tanto de materiais e demais suportes pedagógicos quanto de canais e meios de disseminação da produção sobre ensino na saúde, que levou à rediscussão acerca das responsabilidades institucionais e intersetoriais na qualificação do ensino em saúde.

Com isso, sentimos ser possível responder à pergunta, ainda que colocando alguns condicionantes: há pesquisas sobre ensino na saúde no Brasil e elas estão sinalizando para a necessidade de sua sustentabilidade e consolidação. Para que sigam produzindo respostas aos dilemas e às inquietações que justificou o lançamento do Edital CAPES/MS, há de se reivindicar e promover a inclusão da questão do ensino na saúde na agenda de prioridades das instituições de ensino, governamentais e de fomento à pesquisa e dos próprios docentes e preceptores.

Se por um lado existem oportunidades que devem ser aproveitadas e potencializadas, como o desenvolvimento de processos de formação docente exigidos nas Novas Diretrizes Curriculares Nacionais dos Cursos de Medicina ${ }^{29}$ fruto do Programa Mais Médicos, e que podem ser articulados a um pujante processo de produção de conhecimento sobre o ensino em saúde, por outro seria importante, por exemplo, agregar essa temática à Agenda de Prioridades em Pesquisas em Saúde e na retomada dos termos que podem indicar temas e questões a serem aprofundadas pelas instituições de ensino e pesquisa brasileiras nos próximos anos. Devemos garantir pesquisa, formação e inovação no ensino na saúde se pretendemos realizar a profunda mudança nos modelos de formação profissional que a população e o SUS demandam e precisam.

\section{REFERÊNCIAS}

1. Ceccim RB, Carvalho YM. Formação e Educação em Saúde: aprendizados com a saúde coletiva. In: Campos GWS, Minayo MCS, Akerman M, Drumond Júnior M, Carvalho YM. Tratado de Saúde Coletiva. Rio de Janeiro: Fiocruz; 2006. p. 149-82.

2. Magaldi C. Compromisso Social da Escola Médica. Interface. 2011;15(36):327-31

http://dx.doi.org/10.1590/S1414-32832011000100028

3. Ferreira JR. Análisis prospectivo de la educación médica. Educ Med Salud. 1986;20(1):26-42.

4. Schraiber LB. Educação médica e capitalismo: um estudo das relações educação e prática médica na ordem social capitalista. São Paulo: Hucitec; 1989

5. Kisil M, Chaves M. Programa UNI: uma nova iniciativa de educação dos profissionais de saúde. Barueri: Fundação Kellog; 1994.

6. Marsiglia RG. Relação ensino/serviços: dez anos de integração docente-assistencial no Brasil. São Paulo: Hucitec; 1995.

7. Chompré RRS, Egry EY. A enfermagem nos projetos UNI: contribuição para um novo projeto político para a enfermagem brasileira. São Paulo: Hucitec; 1998.

8. Campos GWS. Educação Médica, Hospitais Universitários e o Sistema Único de Saúde. Cad Saúde Pública. 1999;15(1):187-93. http://dx.doi.org/10.1590/S0102-311X1999000100019

9. Almeida M, Feuerwerker L, Llanos CM. A educação dos profissionais de saúde na América Latina: teoria e prática de um movimento de mudança. São Paulo: Hucitec; Lugar Editorial; 1999. p. 47-81.

10. Merhy EE. Apostando em projetos terapêuticos cuidadores: desafios para a mudança da escola médica (e dos serviços de saúde). In: Merhy EE. Saúde: a cartografia do trabalho vivo. São Paulo: Hucitec; 2002. p. 135-47.

11. Ceccim RB, Feuerwerker LCM. O quadrilátero da formação para a área da saúde: ensino, gestão, atenção e controle social. Physis. 2004; 14(1):41-66.

http://dx.doi.org/10.1590/S0103-73312004000100004
12. Marins JJN, Rego S, Lampert JB, Araújo JGC. Educação médica em transformação: processos de mudança e construção de realidades. São Paulo: Hucitec; 2004.

13. Bollela VR, Germani, ACCG. Campos HH, Amaral E. Educação baseada na comunidade para as profissões da saúde: aprendendo com a experiência brasileira. In: Cyrino EG, Figueiredo AM, Lopes CV, Monteiro EM, Fronza FL, Santos FL, et al. Políticas públicas indutoras de mudanças nas graduações da saúde na perspectiva do fortalecimento do Sistema Único de Saúde do Brasil: os caminhos, a evolução e os desafios do Pet-Saúde. v.1. Ribeirão Preto: FUNPEC; 2014. p. 37-53

14. Brasil. Ministério da Educação. Reestruturação e Expansão das Universidades Federais (Reuni). Disponível em: <http://portal.mec. gov.br/index.php?ltemid=1085>. Acesso em: 14 fev. 2011.

15. Cyrino EG, Pinto HA, Oliveira FP, Figueiredo AM. The Project "Mais Médicos" and training in and for the Brazilian Health System (SUS) why change it? Esc Anna Nery. 2015;19(1):5-6. http://dx.doi.org/10.5935/1414-8145.20150001

16. Comissão Interinstitucional Nacional de Avaliação do Ensino Médico (CINAEM). Preparando a transformação da escola médica brasileira: Projeto CINAEM - III fase relatório 1999-2000. CINAEM; 2000

17. Brasil. Ministério da Saúde. Secretaria de Gestão do Trabalho e da Educação na Saúde. Convocatória para apresentação de experiências de ensino na formação de profissionais para a integralidade em saúde. EnsinaSUS/Lappis - DEGES/MS. Brasília: Ministério da Saúde; 2004. p. 10-5.

18. Lima VV, Feuerwerker LCM Padilha RQ, Gomes R, Hortale VA. Ativadores de processos de mudança: uma proposta orientada à transformação das práticas educacionais e da formação de profissionais de saúde. Ciênc Saúde Colet. 2015;20(1):279-88.

http://dx.doi.org/10.1590/1413-81232014201.21992013

19. Morosini MC. Docência Universitária e o futuro: desafios e possibilidades In: Fernandes CMB, Grillo M. Educação superior: travessias e atravessamentos. Canoas: ULBRA; 2001. p. 11-31. 
20. Binder MCP, Magaldi C, Lopes RM. Internato de saúde pública na Faculdade de Medicina de Botucatu. Educ Med Salud. $1981 ; 15(2): 142-50$

21. Chemello D, Manfroi WC, Machado CLB. O papel do preceptor no ensino médico e o modelo preceptoria em um minuto. Rev Bras Educ Med. 2009;33(4):664-9 http://dx.doi.org/10.1590/S0100-55022009000400018

22. Saviani D. Escola e Democracia. Campinas: Autores Associados; 2008.

23. Brasil. Ministério da Educação. Coordenação de Aperfeiçoamento de Pessoal de Nível Superior (CAPES). Diretoria de Programas e Bolsas no país - DPB. Coordenação Geral de Programas Estratégicos - CGPE. Coordenação de Indução e Inovação Cll. Pró-Ensino na Saúde: Edital Nº 024/2010. Disponível em: $<$ http://www.capes.gov.br/images/stories/download/bolsas/Edital EnsinoSaude_2010.pdf>. Acesso em: 10 ago. 2015.

24. Brasil. Ministério da Educação. Coordenação de Aperfeiçoamento de Pessoal de Nível Superior (CAPES). Programa atua na consolidação da formação dos profissionais da saúde. Escrito por Assessoria de Imprensa da Capes. Disponível em: <http://www. capes.gov.br/36-noticias/4164-programa-atua-na-consolidacaoda-f>. Acesso em: 10 ago. 2015

25. Bahia SHA, Batista SH, Batista NA. O ensino na saúde como objeto de pesquisa na pós-graduação stricto sensu: uma análise do programa Pró-Ensino na Saúde: texto para exame de qualificação de doutorado. Programa interdisciplinar em ciências da saúde. Pró-Ensino na Saúde. UNIFESP: Campus Baixada Santista; 2015.

26. Brasil. Ministério da Educação. Coordenação de Aperfeiçoamento de Pessoal de Nível Superior (CAPES). Documento produzido no Seminário Nacional: Mestrados Profissionais em Ensino na Saúde, 16 e 17 de março de 2010. Disponível em: <https://www.capes.gov. $\mathrm{br} /$ images/stories/download/diversos/Seminario_EnsinoSaude. pdf>. Acesso em: 22 ago. 2015

27. Batista NA. Desenvolvimento docente na área da saúde: uma análise. Trab Educ Saúde. 2005;3(2):283-94 http://dx.doi.org/10.1590/S1981-77462005000200003

28. Brasil. Ministério da Saúde. Secretaria de Gestão do Trabalho e da Educação na Saúde. Departamento de Gestão da Educação na Saúde. Política de educação e desenvolvimento para o SUS: caminhos para a educação permanente em saúde. Brasília: Ministério da Saúde; 2004.

29. Brasil. Associação Brasileira de Mantenedoras de Ensino Superior (ABMES). Resolução CES/CNE n 3, de 20 de junho de 2014. Institui diretrizes curriculares nacionais do curso de graduação em medicina e dá outras providências. Disponível em: <http://portal.mec.gov.br/ index. php?option=com_content\&id=20138\&ltemid=866>. Acesso em: 21 ago. 2015 